This paper also describes an experimental investigation at a wave-length of about $1.25 \mathrm{~m}$. of the radiation pattern produced by a half-wave-length aerial in a corner reflector with angles of $90^{\circ}, 60^{\circ}$ or $45^{\circ}$. Using sheets one and a half wave-lengths high and two wavelengths wide, it was found that the radiation distribution is not appreciably modified if the apex of the reflector is amputated and the resulting hole closed by a flat sheet. Such a modified reflector affords a saving in space and also shows that the pattern is insensitive to the shape of the back of the reflector. Other experiments showed that the performance of this type of aerial system was inappreciably affected if the continuous reflecting sheots were replaced either by wire netting with a mesh about one fortieth of a wave-length inside, or by a comb of open rods about half a wave-length long.

In the course of the second paper, $H$. Page described some measurements of the performance of various horizontal dipole arrays operating on wavelengths in the region of 15-20 metres as used at stations of the British Broadcasting Corporation. The main method of measurement adopted consisted in elevating a calibrated frame receiving aerial by means of a captive balloon; by varying the height and position of the balloon, the field strengths in different directions from the transmitting array were determined. In a second method, a frame aerial at ground-level was used; this gave only relative values of field strength and was used mainly to determine variations in the performance of the aerial array as the radio frequency in use was altered over a small band.

It was found that for an aerial array radiating over a flat site free from obstacles, there was good agreement between the theoretical and measured perform. ance : the maximum field strength was of the order of $0.8-0.9$ of the theoretical value. A sloping site or the existence of other nearby arrays may, however, cause appreciable departures from the theoretical characteristics. In particular, it was found that the loss of power in radiating through other aerial array systems may be as much as 40 per cent in some cases; and this loss is not necessarily associated with a resonant condition in the obstructing array.

It is concluded from this work that, in order to obtain the best efficiency in short-wave transmitting aerial arrays, these should be erected on as flat a site as possible and should be arranged to avoid radiation through other arrays ; distant obstructions which intercept part of the main lobe of radiation should also be avoided.

\section{'MINOR' ELEMENTS IN PLANT NUTRITION}

$\mathrm{O}$ UR knowledge of the precise physiological functions of the so-called 'minor' elements in plant nutrition has not kept pace with the growing realization of their importance in agricultural and horticultural practice. A number of papers in the Proceedings of the American Society of Horticultural Science report the effects of certain minor elements on crop growth and behaviour. R. D. Dickey and M. Drossdoff $(42,74 ; 1943)$ show that $2 \mathrm{lb}$. of manganese sulphate per tree applied to the soil cured frenching of the leaves of the tung (Aleurites fordii), due to manganese deficiency. The same authors
(42, $79 ; 1943)$ describe a 'cupping' of the terminal leaves of the tung, which are reduced in size and show an interveinal chlorosis and sometimes an apical and marginal browning. This may be followed by leaf abscission and shoot die-back; the condition can be cured by applying copper sulphate (1/16 oz. per tree) to the soil. That the disease is due to copper deficiency and the ameliorative effects of the soil dressings of copper sulphate are not due to any indirect effect, is shown by the fact that spraying with copper sulphate is equally effective in curing the disease.

J. G. Maclean, W. C. Sparks and A. M. Binkley $(44,362 ; 1944)$ in a manurial experiment with potatoes in an alkaline soil $(p H .8 \cdot 5)$ supplied the sulphates of iron, copper, zinc and manganese (25 lb. per acre) alone and in all possible combinations, in addition to adequate dressings of nitrogen, potash and phosphate. Besides noticeable effects on crop yields due generally to effects on tuber size rather than the number of tubers, all the treatments, except copper + iron + zinc, copper + zinc + manganese, iron + zinc, copper + manganese, and zinc + manganese, increased the thickness of the periderm of the tuber significantly. Whether or not a thickened periderm will reduce tuber damage during harvest and marketing remains to be seen, but the possibilities in this direction need no stressing. Effects of minor elements on skin colour of tuber of Red McLure potatoes are reported by W. C. Sparks (44, $369 ; 1944)$, who found that all combinations of minor elements tried increased tuber colour in the field, but the effect was greatest when iron, alone or in combination with copper or copper and manganese, was supplied.

Significant effects on carrots and turnips of application of borax, copper sulphate, manganese sulphate and zinc sulphate, to soils in which the crop showed no deficiency symptoms, are described by G. H. Harris $(43,219 ; 1943)$. The effect varied on the different soils (but copper always increased root yield) and yield, sugar content and keeping qualities of the roots were all affected by the treatment.

\section{CYTOPLASM, VACUOLE AND CELL-WALL MAGNITUDES IN DIPLOID AND TETRAPLOID BARLEY}

$I^{\mathrm{N}}$

$\mathrm{N}$ the larger cells of a 'gigas' or 'semi-gigas' allotetraploid, is the increase due to proportionate increases in the cytoplasm, the vacuoles and the cell-walls, or is it mainly due to an increase in one alone or in two of these ? By careful analyses of the water, ash, sugar, 'protein', nitrogen, etc., contents of diploid and tetraploid plants of a single variety of barley, Hordeum vulgare, grown under constant nutrient conditions in photothermostats, I. Ekdahl (Arkiv för Botanik (Stockholm), 31, No. 5, 1 ; 1944) is able to draw some interesting conclusions. Tetraploid leaves assimilate more slowly but have a higher proportion of their dry weight as sugar and ash than diploid leaves, but if this extra sugar and ash is deducted from the total dry weight, a 'residual' dry weight for 'protein', cell-wall, etc., is obtained which is the same in both tetraploid and diploid leaves. Calculated on the residual dry weight, fresh tetra- 